\title{
Autologous mDC3/8-KRAS Vaccine
}

National Cancer Institute

\section{Source}

National Cancer Institute. Autologous mDC3/8-KRAS Vaccine. NCI Thesaurus. Code C162269.

An antineoplastic vaccine composed of autologous mature dendritic cells (mDCs) pulsed with mutant KRAS peptides specific to a patient's tumor mutation and human leucocyte antigen (HLA) type, with potential immunostimulating and antineoplastic activities. Upon administration, this vaccine, which is administered as an mDC3 primer, followed by an mDC8 booster, may elicit a cytotoxic T-cell $(C T L)$ response against cancer cells expressing certain KRAS mutations. K-RAS, a member of the RAS family of oncogenes, serves an important role in cell signaling, division and differentiation. Mutation of K-RAS may induce constitutive signal transduction leading to tumor cell growth, proliferation, invasion, and metastasis. 